\title{
Research on integrating relevant resources to improve the humanistic quality of competitive sports reserve talents in china
}

\author{
Zhang Fan* \\ Department of Police Skills and Tactics, Nanjing Forest \\ Police College \\ Sports Science postdoctoral programme, Nanjing Normal \\ University \\ Nanjing 210023, China \\ zhangfan@nfpc.edu.cn
}

\author{
Zhou Bo \\ Department of Police Skills and Tactics, \\ Nanjing Forest Police College \\ Nanjing 210023, China \\ zhoubo@nfpc.edu.cn
}

\author{
Jia Changzhi \\ Department of Police Skills and Tactics, \\ Nanjing Forest Police College \\ Nanjing 210023, China \\ jiachangzhi@nfpc.edu.cn
}

\begin{abstract}
Prize and education are the essence of competitive sports, but its ultimate purpose is to realize people's subjectivity, to practice the ethical value of universal justice, equality and harmony, and to lead to the gold medal with humanities. And the integration of humanities and sports is demands of the time. In this study, disscuss how to promote the humanistic quality education of competitive sport reserve talents through Integrating four construction of Humanistic Quality Education, so as to promote the coordinated development for reserve talents' body, heart, skill and ability. Finally, at least under the current training mode, whatever they become the elite athletes or take up other jobs into the society in future, the mode will help them make the correct values, norms of behavior pattern, refresh themselves, lay a solid foundation and move forward.
\end{abstract}

Keywords-Humanistic Quality, Competitive Sports, Sports Reserve Talents, Training Environment, School-Based Curriculum

\section{INTRODUCTION}

Humanistic quality refers to the spiritual character of becoming men and the development degree of being talents, including the behavioral tendencies, moral character, cultural accomplishment and aesthetic taste. It is a kind of effort for the athletes to observe the morality of aesthetics, to pursue the spiritual civilization and to improve themselves in the process of the competitive sports' learning, training and competition. Combining it with physical quality, technical and tactical quality, psychological quality as well as intelligent quality, forms the athletes' accomplishment of athletics which is actually the requirement for "people's" all-round development Because the subjects of competitive sports are athletes, as social men, they must have the people's social attributes, which requires the strengthening of humanistic quality training on competitive sports' talents, so that they can achieve allround development in the future [1]. However, many evidences show that the current talent training of competitive sports is lack of humanistic quality education, which has affected the transition from "ideological formation" to "gradually fixed ideology". It has caused negative impacts on the growing youth. Therefore, the competitive sports' talents training should not only take into account the requirements of future career for sports skills, but also fully consider whether their comprehensive quality meets the needs of society. In the training process, the reserve athletes should not obtain excellent athletic performance at the expense of ideas, culture, psychology, ability and other quality education. The competitive sports cannot ignore that reserve talents are thoughtful, emotional, biological individuals and the competitive sports should be based on humans, with the purpose of the "all-round" development of the reserve talents and sticks to the humanistic quality education. In view of this, this study disscuss how to Integrating four construction of Humanistic Quality Education for Competitive Sports Reserve Talents,so that the humanistic quality education of competitive sport reserve talents can be strengthened.

\section{THE PRINCIPLE OF INTEGRATING RELEVANT RESOURCES TO IMPROVE THE HUMANISTIC QUALITY OF COMPETITIVE SPORTS RESERVE TALENTS}

First, it should be comprehensive and hierarchical. And the first of it is to accurately grasp all aspects of humanistic quality education, and do a good positioning work at the same time. At this stage, quite a number of competitive sports schools also compile relevant contents of humanistic quality education in the process of training young athletes. However, 
it is not perfect enough on the whole, because most of the content involved is only the accessory of culture courses and training courses, which does not receive sufficient attention. Besides, it has poor practical applicability and limited pertinence. Young athletes have different kinds of personalities because of the differences in age, family environment and social environment. If the humanistic quality education ignores the individual differences, and takes the education without discrimination, it will inevitably lead to this situation where education is confined to the form, and is difficult to further develop toward humanistic quality, and is more difficult to sublimate into humanistic spirit and other related contents. Therefore, the humanistic quality education of young athletes should be targeted and hierarchical. As a whole, young athletes are generally younger (usually between 6 and 18 years). As for the contents of humanistic quality education which require a strong sense of awareness and insight, it is better to choose the simpler contents and educate young athletes in a lively form.

Second, it should have diversity and flexibility. The implementing modes and ways of humanistic quality education must be suitable for the characteristics of educational subjects (young athletes), and should be diversified and flexible. It is difficult to achieve the desired results by merely relying on establishing some humanistic courses or holding several lectures to improve humanistic quality. Competitive sports schools should fully explore the educational contents with humanistic spirit, comprehensively use the kinds of educational forms and means, and integrate various factors and forces of the humanistic quality education, so as to form a strong atmosphere of it. Only in this way can we achieve the desired effects. In addition, competitive sports schools also need to strengthen the construction of campus culture, try their best to show the function of the second classroom, create a campus culture system with a rich humanistic spirit, and make use of colorful and diverse humanistic activities to fully stimulate the students' related spirits, which is more important for those younger athletes. At the same time, we should make full use of the humanistic educational resources outside the school to make up for the lack of it in competitive sports schools, such as cultural teaching and project hosting.

\section{INTEGRATING FOR CONSTRUCTION OF HUMANISTIC QUALITY EDUCATION FOR COMPETITIVE SPORTS RESERVE TALENTS}

\section{A. Teaching Staff Construction}

We worked for the establishment of high standard teaching staffs with general knowledge as well as the professional training theories. Apart from professional knowledge and high cultural quality, the teaching staffs should improve their humanistic spirits, emotions, attitudes and values so as to build a dynamic knowledge structure of multi-sequences, multielements and multi-levels. That is to say, the first was the basic theoretical knowledge of humanity, which was the mother of humanistic quality education. The second was theoretical knowledge of education for it was indispensable in the process of being a good teacher and teaching well for reserve talents [2]. The third was the specialized theoretical knowledge for it determined the direction of teachers of literary class and coaches.

Build a team of teachers with both professional and humanistic qualities. Teachers and coaches should have some ability and quality objectives. The first one is the organizational coordination ability. They should be able to integrate their own humanistic spirit, humanistic quality and sound values into the process of cultural knowledge teaching or special training. The second one is the scientific research ability. The main work of teachers who teach the general cultural knowledge and coaches who train the special skills is to realize the organic integration of theoretical knowledge and training. The sole guarantee for the promotion of their teaching capabilities and theoretical skills is the scientific research work. The third one is the innovative thinking ability. Because of the particularity of teaching and training reserve talents, teachers and coaches are not only required to think independently, but also influence and motivate students with innovative thinking in the process of their accepting knowledge and skill to form the perfect personality.

\section{B. School-Based Curriculum Construction}

Based on some uncoordinated features in the overall competitive sports humanistic quality development of the reserve talents and ignorance of humanistic quality education, it is necessary to re-examine the necessity and urgency of constructing sports humanities quality school-based curriculum for training subjects. We should not only realize the importance of humanistic quality to reserve talents' growth, but also realize the benefits of implementing the humanistic quality school-based curriculum construction to the sustainable development of competitive sports schools.

Construct the curriculum system to meet teachers and coaches' humanistic quality development needs. Adequate training and opportunities for participation in the development of courses should be provided to meet teachers' needs of the professional development [3]. Change the identity of cultural teachers who was the single performer and bring coaches to the implementation level of school-based curriculum. The teaching, training and thinking need to be changed to establish connection between the cultural class and the training class, and thus knowledge of school-based curriculum can be extended and the humanistic quality knowledge system can be improved in two classes.

Construct the curriculum system to meet the humanistic quality development of reserve talents in competitive sports. Training subjects need to, not only lay a foundation for reserve talents' glory for the country and excellent athletic performance in the future, but also make preparation to improve reserve talents' quality. Therefore, the construction of humanistic quality school-based curriculum should focus on reserve talents' future development, and development and utilization of curriculum with the actual development demand of reserve talents as the main part.

Construct the curriculum system to meet needs of training subjects' humanistic quality education. In the special competitive sports education field [4], we should firmly grasp 
universal law that is development of people should be active and comprehensive, which can help reserve talents not only build and shape their overall sports skills in limited time, but also fully develop themselves in the self-cultivation, humanistic knowledge, humanistic spirit and morality

\section{Training Environment Construction.}

Build an educating culture and create a humane environment. In many functions, the function of educating people is the most important. Whether the tangible or intangible humane atmosphere, it has a good moisturizing effect for physical and mental growth of reserve talents, which can effectively regulate and inspire their thinking and behavior, and improve personality. It plays an important role for improving the ideological and moral qualities. Creating a strong cultural atmosphere in campus can make a subtle influence on reserve talents, guide them reflect themselves spontaneously, form good quality and behavior, take the initiative to shoulder responsibilities and obligations and actively get involved in learning and training practice.

Build a facility culture and create a humane environment. Beauty should be the soul of training subjects' human environment. Enjoying beauty, inspiring beauty, and immersing in the beauty can make reserve talents pleasant and sublimate their emotion [5]. Training subjects set up a personalized and fine facility culture, which not only has certain promotion significance to the humanities campus environment construction, but also can promote reserve talents to get a certain education in this kind of environment. Although the construction of the environment can not represent the human culture as a whole, however, from a certain point of view, with the help of the humanistic environment, training subjects improve the humanistic atmosphere and the level of running schools.

Build a spiritual culture and create a humane environment. The cultural concepts, the purpose of running schools and the atmosphere of humanistic spirit of each training subject, the outlook of the world, life and values and morality of the reserve talents and the school motto, school spirit, style of study and training and others are basic components of spiritual culture. They can truly represent the humanistic environment level of the school. And they will change with the campus cultural traditions, regional characteristics and historical background. Therefore, the core campus spiritual culture presents a high degree of abstract quality characteristics and value pursuit. It is that training subjects own a group mentality with strong stability and ideology [6]. After a long period of training experience, training subjects accumulate a spiritual consciousness which has a certain representative function. It can fully embody the educational idea, qualification, character, appeal, vitality and comprehensive strength of the training subject

\section{Evaluation System Construction}

Construct the evaluation system with both competitive skill and humanistic quality to promote the training subjects' development. Although part of the training subjects try to gradually reform the shortcomings of the traditional training model, it is difficult to change in the short term when the cultural background is slightly inadequate in the process of training. Therefore, it is necessary to establish a humanistic education evaluation system which aims to cultivate reserve talents' independent personality, health psychology, and which has a certain competitive advantage in the innovation and social adaptation. To realize the scientificity and rationality of the humanities education evaluation mechanism, we should strengthen the design of humanities disciplines from multi-level, such as the promotion the combination of teaching and training-teacher and coach-campuspractice-evaluation, to put theory and practice in the same importance, to better merge competitive talent training and humanistic quality education, so that reserve talents can unify the gold medal and being a man together.

Constructing an evaluation system with both sports intelligence and innovation consciousness can lay a solid foundation for the sustainable development of an athletes' sports career. The evaluation system will help reserve talents to develop innovative thinking, enhance the level of innovation, expand horizons and enhance self-awareness through effective innovative thinking education. In addition, we can shape a strong creative interest in sports training, and train reserve talents to become men with creativity and ability of sustainable development, and in their sports career, they constantly improve their personality connotation, sports intelligence and collaborative intelligence.

Construct an evaluation system with both competitive beliefs and perfect personality and cultivate competitive sports talents with strong humanistic quality $[7,8]$. If they want to realize the improvement of humanistic quality, reserve talents must actively adjust their personal attitude, strengthen their faith, and make clear the ultimate goal and direction of efforts. They struggle tenaciously in the competitive process and correctly know the ability of themselves, interpersonal skills and the ability to manage emotions. They have an excellent individual mind, good motivation, elegant temperament, broad interests, stable and distinct personality. Carrying out humanistic quality education evaluation, through understanding the rise and fall of history, honor of country, clear philosophy, the creative thinking, realizes the grace of etiquette, instrument, temperament, gesture and body, remains sound mind, perfect personality, good thoughts, good character, strong will, optimistic personality, and open mind to shape a well mental outlook and a well spirituality.

\section{SUMMARY}

At present, there is a predicament in the mode of cultivation competitive sports reserve talents. In addition to the reform from the national system level, it is the key point that all the training subjects should strengthen humanistic quality education. Because the subjects of competitive sports is the starting point for athletes who engage in the competitive sports, and it is also the starting point for cultivating their correct outlook on life, values and the world. Indeed, prize and education are the essence of competitive sports, but its ultimate purpose is to realize the people's subjectivity, to practice the ethical value of universal justice, equality and harmony, and to lead to the gold medal with humanities. The 
integration of humanities and sports is demanded of the time and is also the purpose of this study.

\section{ACKNOWLEDGEMENT}

This work was supported in part by the Project of the Fundamental Research Funds for the Central Universities under Grant LGZD201709, in part by the Project of China Postdoctoral Science Foundation under Grant 2017M611849, in part by Jiangsu Qing LAN Project under Grant 2017, and in part by Nanjing Forest police College Teaching Reform Project under Grant ZD17001 \& YB17001.

\section{REFERENCES}

[1] DUAN Wenge, DUAN Yuan-yuan. Demands of the ethical values of competitive sports. Journal of Social Science of Hunan Normal University. Vol. 39 (2010) No. 5, p. 30-33. (In Chinese)

[2] YANG Huzhi, WANG Le, MA Wei-ping. Discussion on Humanistic Quality Education of athletes. Journal of Sport. Vol. 31 (2011) No. 12, p. 4-5. (In Chinese)
[3] ZHANG Fan, WEI Peng, LIU Ming, et al. Research on the cultivation of competitive sports reserve talents based on the theory of Multiple Intelligences. Guizhou Sports Science and Technology. Vol. 31 (2011) No. 12, p. 4-5. (In Chinese)

[4] TANG Shaoqing. Comparison of the whole person education model in China and foreign countries. Social Scientist. Vol. 26 (2014) No. 12, p. 110-118. (In Chinese)

[5] MA Zhihe, XU Hongwei, LIU Zhuo. Innovation on Cultivation System of Sports Talent Reserves in China. Sports Science. Vol.24 (2004) No. 6 , p. 56-59. (In Chinese)

[6] ZHU Jie, ZHANG Fan, WANG Changsheng, et al. Construction of the Influential Factors Model for the Deviation of Humanistic Quality of Athletic Reserves in China. Journal of Guangzhou Sport University. Vol 36 (2016) No. 6, p. 15-22. (In Chinese)

[7] WANG Xiang-hong, LI Yepeng. The Research on the Developing directions of the Cultivating System of Competitive Reserved Talents in China. Journal of Capital College of Physical Education. Vol. 23 (2011) No. 5, p. 402-404. (In Chinese)

[8] SHI Y.J. Humanistic quality theory. People's University of China press, 2008, p. 21-22. (In Chinese) 